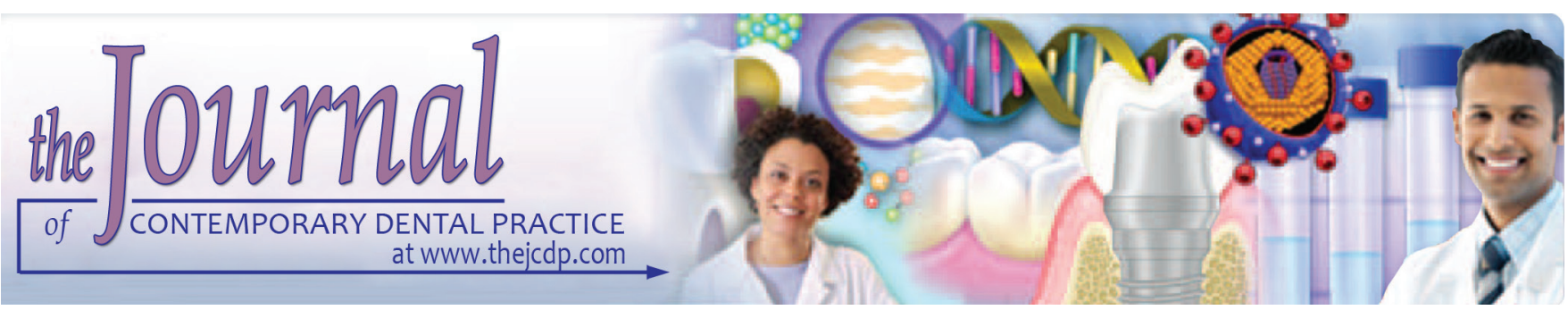

\title{
Assessment of Coronal Leakage of Temporary Restorations in Root Canal-treated Teeth: An in vitro Study
}

${ }^{1}$ Pankaj K Srivastava, ${ }^{2}$ Ajay Nagpal, ${ }^{3}$ Gaurav Setya, ${ }^{4}$ Sunil Kumar, ${ }^{5}$ Alankrita Chaudhary, ${ }^{6}$ Kuldeep Dhanker

\begin{abstract}
Introduction: Coronal leakage is one of the constant concerns in routine dental practice. It is one of the factors responsible for the failure of root canal therapy. Permanent restorations should be given as soon as possible after the completion of root canal therapy. If unavoidable, provisional restoration should be given in such a way that it maximally reduced the leakage of microorganisms and fluids from the external environment into the canal space. Hence, we evaluated the effect of saliva on the coronal leakage of temporary restorations.
\end{abstract}

Materials and methods: Biomechanical preparation of the root canals of 204 fresh mandibular first premolar teeth was done using endodontic files with intermittent irrigation of sodium hypochlorite solution and ethylenediaminetetraacetic acid. Alternate irrigation with normal saline was done periodically. After preparation, drying of the canals was done using paper points followed by sealing of the apical foramen. For the assessment of the microleakage, Siqueira et al apparatus and method was used. All the specimens were divided into four groups based on the provisional restorative material used. All the groups were further divided into three subgroups based on the presence and absence of intracanal medicaments. Verissimo et al's criteria were used to check the turbidity at 1-, 2-, 3-, and 4 -week interval respectively. All the results were analyzed by

\footnotetext{
${ }^{1}$ Department of Dentistry, Ganesh Shankar Vidyarthi Memorial Medical College, Kanpur, Uttar Pradesh, India

${ }^{2,4}$ Department of Conservative Dentistry and Endodontics, K.D. Dental College \& Hospital, Mathura, Uttar Pradesh, India

${ }^{3}$ Department of Conservative Dentistry and Endodontics Sri Gobind Tricentenary Dental College, Hospital \& Research Institute, Gurugram, Haryana, India

${ }^{5,6}$ Department of Public Health Dentistry, School of Dental Sciences, Sharda University, Greater Noida, Uttar Pradesh, India

Corresponding Author: Gaurav Setya, Department of Conservative Dentistry and Endodontics, Sri Gobind Tricentenary Dental College, Hospital \& Research Institute, Gurugram Haryana, India, Phone: +919501544877, e-mail: drgauravsetya@ gmail.com
}

Statistical Package for the Social Sciences (SPSS) software. Chi-square test was used to measure the level of significance, and $p<0.05$ was considered to be significant.

Results: In group I, all the subgroups' specimens showed significant difference at 1 week's time. Only the subgroup with no intracanal medicaments in Cavit-containing provisional restoration showed nonsignificant alterations. Statistically significant alterations were seen at 1,2 , and 3 weeks' interval in all the subgroups except for one with intracanal medicaments.

Conclusion: All the temporary restorative materials were not able to prevent microleakage after 1 week's time, with worst bacterial resistance shown by Ketac Molar and ionomer restorative material. Future studies are advocated for better prognosis of root canal therapy.

Keywords: Leakage, Provisional, Restoration.

How to cite this article: Srivastava PK, Nagpal A, Setya G, Kumar S, Chaudhary A, Dhanker K. Assessment of Coronal Leakage of Temporary Restorations in Root Canal-treated Teeth: An in vitro Study. J Contemp Dent Pract 2017;18(2):126-130.

\section{Source of support: Nil}

Conflict of interest: None

\section{INTRODUCTION}

One of the constant concerns in routine dental practice in restorative dentistry is coronal leakage. Failure of root canal treatment is one of the common outcomes of such complication. ${ }^{1}$ Failure usually occurs in the time period in which tooth is in between the stage of endodontic session and final restoration, i.e., in the phase of temporization. Pathway of the fluid from the oral cavity into the tooth through the restorative material is known as microleakage. $^{2}$ It is of great significance for dentists since it occurs around provisional temporary restorations. ${ }^{2,3}$ Therefore, treated teeth should be restored with permanent restorations as soon as possible to avoid coronal leakage. ${ }^{4}$ If 
permanent restoration is not possible in the immediate future, temporary filling should be done in such a way that it seals the coronal portion of the teeth hermetically and should have marginal sealing properties. ${ }^{5}$ Choice of temporary restorative material should be done with great care. It should have properties of abrasion resistance and dimensional stability. At the same time, it should prevent the contact of intracanal medicaments with the oral environment. ${ }^{6}$ There is still lack of evidence in the literature regarding the effect of saliva on temporary restorations. ${ }^{7}$ Hence, we evaluated the effect of saliva on the coronal leakage of temporary restorations.

\section{MATERIALS AND METHODS}

In this in vitro study, a total of 204 mandibular first premolar teeth were included for the study. Only fresh caries-free teeth were extracted for the study. Biomechanical preparation of the root canals was done using endodontic files. Intermittent irrigation by sodium hypochlorite and ethylenediaminetetraacetic acid was done in between the filing procedure with a syringe. Alternate irrigation with normal saline was done periodically. After the completion of biomechanical preparation, drying of the root canals was done with paper points. Sealing of the apical foramina was done using cyanoacrylate followed by insertion of the root portion into an Eppendorf tube, leaving the crown portion of the tooth outside exposing the crown to external environment (Fig. 1). Siqueira et al apparatus and method were used for assessment of leakage. ${ }^{8}$ The specimens were then autoclaved for $20 \mathrm{~min}$ at $121^{\circ} \mathrm{C}$. Depending on the type of coronal seal used, all the study specimens were randomly divided into four groups with 51 teeth in each group as shown in Table 1.

Based on the type of medicament (intracanal) used, all the groups were further divided into three subgroups as shown in Table 2.

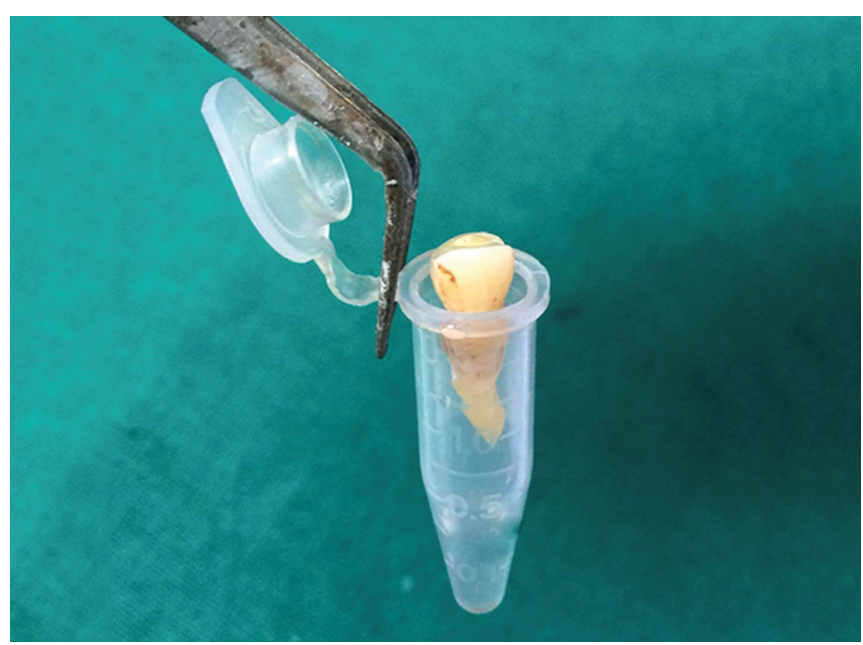

Fig. 1: Isolated crown portion of the tooth with root immersed in study solution in Eppendorf tube
Positive controls were the samples in which neither any medicament was used nor were any coronal restoration placed. Cavity depth was approximately $3.5 \mathrm{~mm}$ from the base of pulp chamber to the cavosurface margin. ${ }^{9}$ After placement of the medicaments and cotton pellets in the pulp canals and pulp chamber respectively, the teeth samples were filled with provisional restorations depending on their respective groups. Before microleakage test, the teeth specimens were left for about 1 hour. Vial tube was filled with brain heart infusion (BHI) agar using sterile pipettes. To stop the penetration of saliva into the BHI broth, cyanoacrylate was placed between the flask and the stopper. Collection of human saliva was done from volunteers and both the saliva and broth were maintained at a ratio of 25:75 and placed on the crown two times daily. Incubation of the apparatus was done at $37^{\circ} \mathrm{C}$ following the criteria of Verissimo et al to check the turbidity. ${ }^{10}$ Periodic checking of turbidity was done at 1-, 2-, 3-, and 4-week intervals respectively. All the results were analyzed by Statistical Package for the Social Sciences (SPSS) software. Chi-square test was used to measure the level of significance, and $p<0.05$ was considered to be significant.

\section{RESULTS}

Graph 1 shows percentage of leakage in different groups. Significant results were obtained while comparing the negative controls at 1 week, 2 week and 3 week time (Table 3). Table 4 highlights the p-value for percentage of leakage for different subgroups of Group 1. All the subgroups in the group 1 specimens showed significant

Table 1: Division of specimens depending on the type of coronal seal

\begin{tabular}{ll}
\hline Groups & Type of coronal seal used \\
\hline I & Coltosol F (ColteneWhaldent) \\
II & Cavit (3M ESPE) \\
III & Ketac Molar (3M ESPE) \\
IV & IRM (Dentsply) \\
\hline
\end{tabular}

Table 2: Division of each group into various subgroups depending on the type of medicament used

\begin{tabular}{ll}
\hline Subgroups & Type of medicament used \\
\hline i & No medication \\
ii & $\mathrm{CaOH}$ \\
iii & $\mathrm{CHX}$ \\
\hline
\end{tabular}

Table 3: $p$-value for percentage of leakage for negative control

\begin{tabular}{llll}
\hline & \multicolumn{3}{c}{$p$-value (percentage of leakage) } \\
\cline { 2 - 4 } Group & After 1 week & After 2 weeks & After 3 weeks \\
\hline Negative control & $0.00018 \mathrm{~S}$ & $0.00018 \mathrm{~S}$ & $0.00018 \mathrm{~S}$
\end{tabular}

S: Significant 
Table 4: $p$-value for percentage of leakage for different subgroups of group I

\begin{tabular}{llll}
\hline & \multicolumn{3}{c}{$p$-value (percentage of leakage) } \\
\cline { 2 - 4 } Groups & After 1 week & After 2 weeks & After 3 weeks \\
\hline I (i) & $0.02018 \mathrm{~S}$ & $0.21022 \mathrm{NS}$ & $0.25125 \mathrm{NS}$ \\
I (ii) & $0.00125 \mathrm{~S}$ & $0.00412 \mathrm{~S}$ & $0.00381 \mathrm{~S}$ \\
I (iii) & $0.00715 \mathrm{~S}$ & $0.00842 \mathrm{~S}$ & $0.00152 \mathrm{~S}$ \\
\hline
\end{tabular}

S: Significant; NS: Nonsignificant

Table 6: $p$-value for percentage of leakage for different subgroups of group III

\begin{tabular}{llll}
\hline & \multicolumn{3}{c}{$p$-value (Percentage of leakage) } \\
\cline { 2 - 4 } Groups & After 1 week & After 2 weeks & After 3 weeks \\
\hline III (i) & $0.71823 \mathrm{~S}$ & $0.84586 \mathrm{NS}$ & $0.74445 \mathrm{NS}$ \\
III (ii) & $0.00415 \mathrm{~S}$ & $0.00211 \mathrm{~S}$ & $0.00415 \mathrm{~S}$ \\
III (iii) & $0.00682 \mathrm{~S}$ & $0.00811 \mathrm{~S}$ & $0.00222 \mathrm{~S}$ \\
\hline
\end{tabular}

S: Significant; NS: Nonsignificant

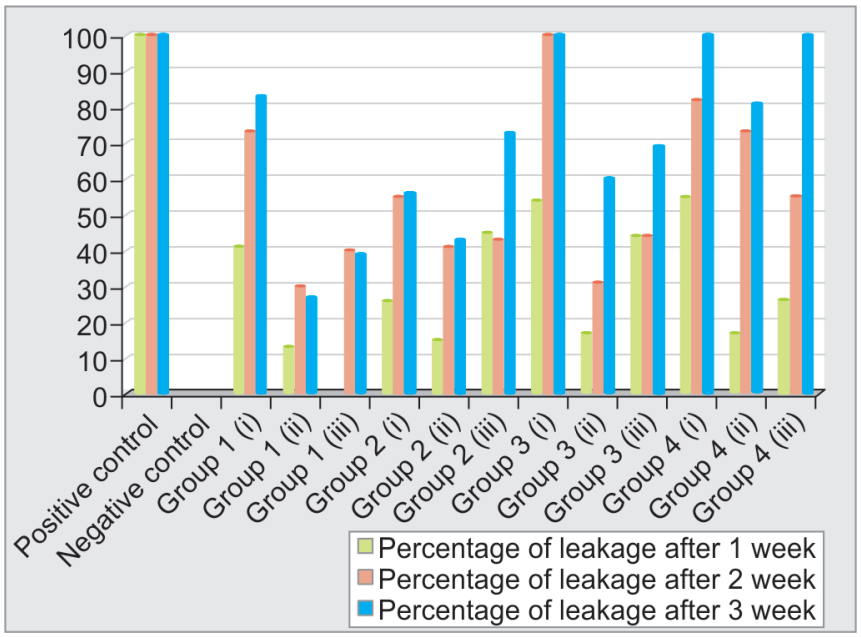

Graph 1: Percentage of leakage in all the groups

difference at one week's time (p-value <0.05). At two and three weeks' time, all the subgroups in Group 1 specimens showed significant results except for subgroup containing no medications. In group with Cavit as provisional restoration, only the subgroup with no intracanal medicaments showed nonsignificant alterations as shown in Table 5. Table 6 shows p-value for percentage of leakage in groups containing Ketac Molar. Statistically significant alterations were seen at 1,2 , and 3 weeks' interval in all the subgroups except for one with intracanal medicaments. In groups containing ionomer restorative material (IRM), significant results were seen only at 1 week's time, as shown in Table 7.

\section{DISCUSSION}

One of the deciding factors in predicting the prognosis of endodontic therapy is the provisional restorative material. The main role of provisional restoration is to temporarily seal the tooth and stop the seepage of fluids, microorganisms,
Table 5: p-value for percentage of leakage for different subgroups of group II

\begin{tabular}{llll}
\hline & \multicolumn{3}{c}{$p$-value (Percentage of leakage) } \\
\cline { 2 - 4 } Groups & After 1 week & After 2 weeks & After 3 weeks \\
\hline II (i) & $0.00125 \mathrm{~S}$ & $0.42512 \mathrm{NS}$ & $0.94852 \mathrm{NS}$ \\
II (ii) & $0.00415 \mathrm{~S}$ & $0.01242 \mathrm{~S}$ & $0.00149 \mathrm{~S}$ \\
II (iii) & $0.00718 \mathrm{~S}$ & $0.00145 \mathrm{~S}$ & $0.00748 \mathrm{~S}$ \\
\hline
\end{tabular}

S: Significant; NS: Nonsignificant

Table 7: $p$-value for percentage of leakage for different subgroups of group IV

\begin{tabular}{llll}
\hline & \multicolumn{3}{c}{$p$-value (percentage of leakage) } \\
\cline { 2 - 4 } Groups & After 1 week & After 2 weeks & After 3 weeks \\
\hline IV (i) & $0.33451 \mathrm{NS}$ & $0.41211 \mathrm{NS}$ & $0.74111 \mathrm{NS}$ \\
IV (ii) & $0.00125 \mathrm{~S}$ & $0.33112 \mathrm{NS}$ & $0.31852 \mathrm{NS}$ \\
IV (iii) & $0.00136 \mathrm{~S}$ & $0.94152 \mathrm{NS}$ & $0.31125 \mathrm{NS}$ \\
\hline
\end{tabular}

S: Significant; NS: Nonsignificant

and other materials from the oral cavity. This results in periapical pathologies once these factors have invaded the periradicular areas. ${ }^{11-14}$ To prevent this, immediate permanent restorations are advocated as soon as possible after completion of the treatment. ${ }^{15,16}$ Data from the past studies indicate that even poorly root canal-treated teeth can have significantly favorable prognosis if provisional restoration placed coronally is well adapted to the margins, thereby preventing penetration of bacteria and other microorganisms. ${ }^{17}$ Hence, we evaluated the effect of saliva on coronal leakage in temporary restorations. In this study, we found that no single temporary restorative material was found to completely prevent bacterial microleakage. Approximately, two-thirds of all the samples showed presence of leakage after 2 weeks' time except for the group with intrapulpal medicaments. In this study, no provisional restorative material was completely resistant to bacterial leakage, with 60 to $70 \%$ of the specimens in all experimental groups demonstrating leakage after 14 days, except with intracanal medicaments (Graph 1 and Tables 4 to 7). Hagemeier et $\mathrm{al}^{17}$ and Jensen and Abbott ${ }^{18}$ have shown that sealing properties of Ketac Molar are less than that of Cavit despite the fact that it performs well under loading pressure. ${ }^{16}$ Even in complex cavities, cavity is still shown to have more efficient sealing abilities. In comparison to Ketac Molar, less leakage was observed after 1, 2, 3, and 4 weeks in this study. However, Liberman et $\mathrm{al}^{19}$ showed that less resistance to load pressure limits the seal ability of Cavit.

Bobotis et $\mathrm{al}^{20}$ showed poor leakage properties of IRM which were in correlation to the results of our study in which we observed presence of high amount of microleakage in samples with IRM as compared with other groups. Time-dependent hygroscopic expansion of Cavit and Coltosol may be responsible for their minimal leakage. However, in Coltosol-subjected groups, fracture 
of the teeth can occur due to expansion occurring in cuspal regions. ${ }^{21}$ To decrease the amount of leakage and bacterial contaminations, medicaments are added in the pulp canal space. ${ }^{22}$ Except for subgroups containing Cavit with chlorhexidine (CHX) and specimens in subgroups CHX with IRM, all other samples showed a comparatively higher leakage in group without intrapulp medicaments as compared with other groups (Tables 4 to 7). We also observed that subgroups containing calcium hydroxide $(\mathrm{CaOH})$ with Coltosol and $\mathrm{CaOH}$ with Cavit showed the presence of minimal microleakage up to 3 weeks' time. Similar results were obtained by Gomes et al and Udayakumar et al who also saw minimal leakage in $\mathrm{CaOH}$-containing subgroups in their respective studies. Symanski et al assessed various temporary restorative materials in Brazilian dental schools, during and after endodontic treatment completion. They prepared a questionnaire and distributed it to 191 schools and found that most of the schools recommend a minimum thickness of $3 \mathrm{~mm}$ for temporary restorations. They further concluded that choice of dental schools regarding coronal restorative materials is subjected to remaining dental conditions. ${ }^{24}$ Veloso et al investigated microbial microleakage through Coltosol, IRM, and Vidrion R after post space preparation. They examined 42 maxillary anterior teeth and observed microleakage daily for 3 months. From the results, they concluded that all provisional fillings and intrapulpal medications did not prevent the accumulation of microorganisms to the root apex. ${ }^{25}$ Cunha et al evaluated the microleakage of temporary sealers and endodontic sealers in 30 bovine teeth. All the teeth were cut at a level of $4 \mathrm{~mm}$ below the cementoenamel junction, and sealing of root canals was done with acrylic resin. From the results, they concluded that microleakage was higher in group containing Sealerplex filling material and Bioplic cap. ${ }^{26}$ Siqueira et al assessed the sealing capacity of $\mathrm{CaOH}-b a s e d$ sealers and from the results concluded that sealers containing $\mathrm{CaOH}$ show higher physical properties as compared with zinc oxide eugenol-containing sealers. ${ }^{27}$ Nelida et al evaluated the sealing ability of X-Temp LC and compared it with Coltosol and Vitro Fill with the help of dye penetration test. From the results, they concluded that all temporary restorative materials show some amount of marginal leakage. However, sealing capacity of X-Temp LC and Coltosol was somewhat better than Vitro Fill glass ionomer cement. ${ }^{28}$ Therefore, for better prognosis and outcome of the endodontic therapy, root canal-treated teeth should be restored with final restoration as soon as possible. Hence, one of the very important aspects which should be stressed on after completion of endodontic therapy is the quality and type of provisional restoration material. ${ }^{23}$

\section{CONCLUSION}

From the above results, it can be concluded that after 1 week's time, all the temporary restorations were not able to stop microleakage, with worst bacterial resistance showed by Ketac Molar and IRM. After 3 weeks' time, no single temporary restorative material could stop leakage to happen coronally. Future studies are advocated to further improve the prognosis of endodontic therapy.

\section{REFERENCES}

1. Zmener O, Banegas G, Pameijer $\mathrm{CH}$. Coronal microleakage of three temporary restorative materials: an in vitro study. J Endod 2004 Aug;30(8):582-584.

2. Zaia AA, Nakagawa R, De Quadros I, Gomes BP, Ferraz CC, Teixeira FB, Souza-Filho FJ. An in vitro evaluation of four materials as barriers to coronal microleakage in root-filled teeth. Int Endod J 2002 Sep;35(9):729-734.

3. Pai SF, Yang SF, Sue WL, Chueh LH, Rivera EM. Microleakage between endodontic temporary restorative materials placed at different times. J Endod 1999 Jun;25(6):453-456.

4. Cruz EV, Shigetani Y, Ishikawa K, Kota K, Iwaku M, Goodis HE. A laboratory study of coronal microleakage using four temporary restorative materials. Int Endod J 2002 Apr;35(4):315-320.

5. Chohayeb AA, Bassiouny MA. Sealing ability of intermediate restoratives used in endodontics. J Endod 1985 Jun; 11(6):241-244.

6. Koagel SO, Mines P, Apicella M, Sweet M. In vitro study to compare the coronal microleakage of Tempit Ultra F, Tempit, IRM, and Cavit by using the fluid transport model. J Endod 2008 Apr;34(4):442-444.

7. Madarati A, Rekab MS, Watts DC, Qualtrough A. Timedependence of coronal seal of temporary materials used in endodontics. Aust Endod J 2008 Dec;34(3):89-93.

8. Siqueira JF Jr, Rôças IN, Lopes HP, de Uzeda M. Coronal leakage of two root canal sealers containing calcium hydroxide after exposure to human saliva. J Endod 1999 Jan;25(1):14-16.

9. Gomes BP, Sato E, Ferraz CC, Teixeira FB, Zaia AA, SouzaFilho FJ. Evaluation of time required for recontamination of coronally sealed canals medicated with calcium hydroxide and chlorhexidine. Int Endod J 2003 Sep;36(9):604-609.

10. Verissimo RD, Gurgel-Filho ED, De-Deus G, Coutinho-Filho T, de Souza-Filho FJ. Coronal leakage of four intracanal medications after exposure to human saliva in the presence of a temporary filling material. Indian J Dent Res 2010 Jan-Mar; 21(1):35-39.

11. Ricucci D, Siqueira JF Jr. Recurrent apical periodontitis and late endodontic treatment failure related to coronal leakage: a case report. J Endod 2011 Aug;37(8):1171-1175.

12. Siqueira JF Jr, Rôças IN, Alves FR, Campos LC. Periradicular status related to the quality of coronal restorations and root canal fillings in a Brazilian population. Oral Surg Oral Med Oral Pathol Oral Radiol Endod 2005 Oct;100(3):369-374.

13. Weston CH, Barfield RD, Ruby JD, Litaker MS, McNeal SF, Eleazer PD. Comparison of preparation design and material thickness on microbial leakage through Cavit using a tooth model system. Oral Surg Oral Med Oral Pathol Oral Radiol Endod 2008 Apr;105(4):530-535. 
14. Williamson AE, Dawson DV, Drake DR, Walton RE, Rivera EM. Effect of root canal filling/sealer systems on apical endotoxin penetration: a coronal leakage evaluation. J Endod 2005 Aug;31(8):599-604.

15. Moreno JO, Alves FR, Gonçalves LS, Martinez AM, Rôças IN, Siqueira JF Jr. Periradicular status and quality of root canal fillings and coronal restorations in an urban Colombian population. J Endod 2013 May;39(5):600-604.

16. Schwartz RS, Robbins JW. Post placement and restoration of endodontically treated teeth: a literature review. J Endod 2004 May;30(5):289-301.

17. Hagemeier MK, Cooley RL, Hicks JL. Microleakage of five temporary endodontic restorative materials. J Esthet Dent 1990 Nov-Dec;2(6):166-169.

18. Jensen AL, Abbott PV. Experimental model: dye penetration of extensive interim restorations used during endodontic treatment while under load in a multiple axis chewing simulator. J Endod 2007 Oct;33(10):1243-1246.

19. Liberman R, Ben-Amar A, Frayberg E, Abramovitz I, Metzger Z. Effect of repeated vertical loads on microleakage of IRM and calcium sulfate-based temporary fillings. J Endod 2001 Dec;27(12):724-729.

20. Bobotis HG, Anderson RW, Pashley DH, Pantera EA., Jr A microleakage study of temporary restorative materials used in endodontics. J Endod. 1989;15:569-572.

21. Laustsen MH, Munksgaard EC, Reit C, Bjørndal L. A temporary filling material may cause cusp deflection, infractions and fractures in endodontically treated teeth. Int Endod J 2005 Sep;38(9):653-657.
22. Gurgel-Filho ED, Vivacqua-Gomes N, Gomes BP, Ferraz CC, Zaia AA, Souza-Filho FJ. In vitro evaluation of the effectiveness of the chemomechanical preparation against Enterococcus faecalis after single- or multiple-visit root canal treatment. Braz Oral Res 2007 Oct-Dec;21(4):308-313.

23. Udayakumar P, Kaushik M, Prashar N, Arya S. Coronal leakage of provisional restorative materials used in endodontics with and without intracanal medication after exposure to human saliva. Saudi Endod J 2016 Dec;6(2):77-81.

24. Symanski NC, Juber P, Morgental RD, Scarparo RK, Vier-Pelisser FV. Temporary restorative materials used by Brazilian dental schools during and after endodontic treatment. Passo Fundo 2013 Jan-Apr;18(1):88-93.

25. Veloso HH, Estrela CR, Decurcio DA, Alves D, Estrela C. Microbial microleakage in temporary restorative materials after post space preparation. Rev Odonto Ciênc 2008 Apr-Jun;23(2):187-191.

26. Cunha CT, de Miranda BF, de Morais JF, Dametto FR, Netoand AF, Chaves LV. In vitro evaluation of coronal microleakage of some temporary sealing materials used in endodontic and three different endodontic sealers. JSM Dent 2014;2(3):1031-1034

27. Siqueira FJ Jr, Fraga RC, Garcia PF. Evaluation of sealing ability, $\mathrm{pH}$ and flow rate of three calcium hydroxide-based sealers. Endod Dent Traumatol 1995 Oct;11(5):225-228.

28. Nelida ASC, Silva NCS, Silva JM, Herrera DR, Nevers AA, Silva EJNL. Assessment of coronal leakage of a new temporary light-curing filling material in endodontically treated teeth. Indian J Dent Res 2014;25(3):321-324. 